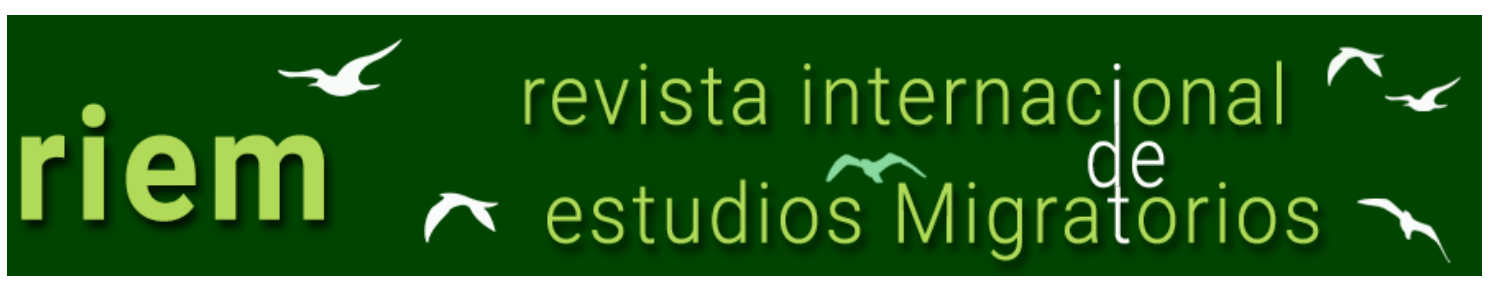

ISSN: $2173-1950$

\title{
Inmigración internacional y sostenibilidad en pueblos pequeños. Retos y oportunidades económicas, ambientales y sociales en el Alt Empordà (Cataluña, España)1
}

Ricard Morén-Alegret ${ }^{2}$ y Cristóbal Mendoza ${ }^{3}$

Resumen: Desde la geografía humana, este artículo pone el foco sobre las percepciones de la sostenibilidad rural que tienen inmigrantes internacionales vinculados a municipios con menos de 500 habitantes. Si las experiencias y opiniones de la población inmigrante fuesen desatendidas, una parte importante de la realidad pasaría desapercibida pues hoy día la inmigración internacional es cualitativamente relevante en muchas áreas rurales de España. Concretamente, este artículo tiene como objetivo responder, entre otras, las siguientes preguntas: ¿Qué dimensiones de la sostenibilidad son destacadas por las personas inmigrantes? ¿cuáles son los principales retos para la sostenibilidad de los micropueblos? ¿cuáles son las propuestas y oportunidades para conseguir pueblos sostenibles? Este artículo aporta resultados basados en un trabajo de campo realizado en el Alt Empordà, incluyendo entrevistas semi-estructuradas a inmigrantes internacionales, así como en trabajo estadístico, documental y cartográfico. Entre la inmigración internacional que reside en los micropueblos del Alt Empordà y que procede mayoritariamente de otros países de Europa y de las Américas (incluyendo emprendedores y empresarios, así como trabajadores experimentados), se pueden escuchar voces cualificadas que plantean diversos retos para la sostenibilidad local, así como oportunidades para el presente y futuro desarrollo rural sostenible. La población inmigrante entrevistada no son un colectivo pasivo sin interés en las actividades

\footnotetext{
${ }^{1}$ Esta propuesta de artículo es una versión ampliada de una comunicación presentada en el XVII Congreso de Población de la Asociación de Geógrafos Españoles (AGE), evento celebrado del 10 al 12 de junio de 2021. Los autores agradecen a los evaluadores anónimos sus comentarios a una versión previa de este texto y agradecen a la organización del mencionado congreso la invitación a enviar este artículo a la REMI.

2 Departamento de Geografía e ICTA, Universidad Autónoma de Barcelona, Bellaterra (Barcelona). España. Correo electrónico de contacto: Ricard.Moren@uab.es.

3 Departamento de Sociología, Universidad Autónoma Metropolitana-Iztapalapa, Ciudad de México, México / MSCA Research Fellow. Departamento de Geografía, Universidad Autónoma de Barcelona, Bellaterra (Barcelona), España. Correo electrónico: cmp@xanum.uam.mx
} 
económicas, el bienestar social o el entorno ambiental de estos municipios, sino que son personas que cuentan con una opinión argumentada sobre el lugar en el que viven. Sugieren, sin duda, ideas de cambio (y de mejora), sobre el medio rural. Mientras estas personas inmigrantes se pueden encarrilar hacia proyectos económicos creativos que permiten interrelación de diferente orden con agentes locales nativos, las dimensiones sociales y especialmente ambientales son de más difícil trato, dado que la población inmigrante, en general, cuenta con relativamente menos mecanismos formales e informales de participación política.

Palabras Clave: Inmigración internacional, desarrollo sostenible, emprendedores y trabajadores cualificados, repoblación en micropueblos, España rural y mediterránea. 


\title{
International immigration and sustainability in small villages: Economic, environmental, and social challenges and opportunities in Alt Empordà (Catalonia, Spain)
}

\begin{abstract}
From a human geography perspective, this paper sheds light on the perceptions of rural sustainability among international immigrants living in municipalities with fewer than 500 inhabitants. If immigrants' views are left unattended, an important part of reality will be lacking in the picture of rural areas because today immigration is qualitatively relevant in rural Spain. This paper aims to answer the following questions, among others: What dimensions of sustainability are underscored? What are the main challenges for sustainability and the proposals or opportunities for improvement? This paper provides research results and insights based on original data gathered during fieldwork in Alt Empordà, including semi-structured interviews with various international immigrants, as well as analyses of documents, maps, and statistics. Most international immigrants residing in small villages of Alt Empordà come from other European and American countries, including entrepreneurs and experimented workers. Some of them have qualified voices that express various current challenges for local sustainability as well as opportunities for the present and future rural sustainable development. The interviewed international immigrant population is active in a variety of projects that take place in small villages of Alt Empordà. There are creative economic projects as well as sustainable businesses run by immigrants that include synergies with various native inhabitants. However, immigrants have more difficulties in tackling the social and environmental dimensions of sustainability due to the relatively scarce political mechanisms that are available for them now.
\end{abstract}

Keywords: International immigration, sustainable development, entrepreneurs and skilled workers, repopulation of small villages, rural and Mediterranean Spain. 


\section{Introducción}

Este artículo investiga, desde la geografía humana, la sostenibilidad de los pueblos pequeños, también denominados micropueblos o en, lengua inglesa, hamlets ${ }^{4}$. La sostenibilidad de algunos micropueblos - definidos como municipios con menos de 500 habitantes - está amenazada debido a factores demográficos como la despoblación (Cloke, 1979 y 1983; Colegio de Geógrafos de Cataluña, 2013; Kasimis, 2010), abriendo a veces el debate sobre su 'ser o no ser' (Morén-Alegret y Wladyka, 2020). Envejecimiento, deficientes comunicaciones (especialmente en transporte público), dispersión de los asentamientos, gentrificación (relacionada con el aumento de segundas residencias) y declive de habitantes permanentes hacen que algunos de estos territorios, a menudo rurales, sean más vulnerables a peligros como incendios forestales, inseguridad o especulación descontrolada (Badia et al., 2014; Blay, 2020; GonzálezHidalgo et al., 2014), de tal forma que incluso la propia existencia de algunos pueblos está amenazada.

A pesar de ello, se vislumbran tendencias positivas en el medio rural que apuntan a nuevas actividades económicas, así como a la reconversión de sectores tradicionales (Tulla, 2019). Por ejemplo, hace ya un cuarto de siglo, se podía leer en un interesante libro especializado: "Hace tan solo unos años lo rural se consideraba un espacio en extinción... Quienes han profetizado el ocaso de lo rural se han equivocado y quienes se empeñan en preservarlo como museo... también yerran. Lo rural no es 'otra sociedad' si no que es parte fundamental de esta... sociedad ya definitivamente multicultural" (Camarero, 1996, p. 125). Hoy día sigue existiendo una relevante diversidad y desigualdad en y entre las áreas rurales, así como en y entre las áreas urbanas (Camarero, 2020). Durante las últimas décadas, de hecho, la realidad intercultural o multicultural en lugares tanto urbanos como rurales de la geografía española ha enriquecido la sociedad a varios niveles (Zovko, 2019). Así, ha ido surgiendo con los años lo que se denominó como las ‘múltiples caras' de la inmigración internacional en España (Reher y Requena, 2009), tanto respecto a orígenes de las personas inmigrantes como a sus características o destinos geográficos.

Sin embargo, más allá de cuestiones fenotípicas, algunas 'caras' (y cuestiones) de la inmigración internacional son más visibles que otras. Además, incluso en comarcas con

\footnotetext{
4 En inglés, 'hamlet' significa pueblo pequeño (más cercano al trágico vacío o cero demográfico que otros asentamientos humanos más poblados) y, al mismo tiempo, Hamlet protagoniza una universal tragedia existencial de William Shakespeare. El proyecto "HAMLETS. Inmigración y Desarrollo Sostenible en micropueblos" fue financiado por el Programa RecerCaixa, una iniciativa de la Asociación Catalana de Universidades Públicas (ACUP) y de la Fundación 'la Caixa'. Además, este artículo también está relacionado con el proyecto internacional Transmena, financiado por el Ministerio de Economía del Gobierno de España (ref. HAR2016-77876-P).
} 
niveles de desarrollo económico y social relativamente elevados, como el Alt Empordà5 (Girona), se dan procesos de despoblación, estancamiento y/o envejecimiento. En el caso concreto de algunos micropueblos ampurdaneses, se ha observado que la despoblación se ha visto frenada desde los años 1980 por la llegada de inmigrantes internos e internacionales (Playà Maset, 2015; Romagosa et al., 2020). En este artículo, nos centramos en la inmigración internacional y exponemos, entre otras cuestiones, algunos de sus procesos de integración en micropueblos ampurdaneses y, especialmente, las percepciones que tienen diversos inmigrantes internacionales sobre la sostenibilidad local. Concretamente, este artículo tiene como objetivo responder, entre otras, a las siguientes preguntas: ¿Qué dimensiones de la sostenibilidad son destacadas por las personas inmigrantes? ¿cuáles son los principales retos para la sostenibilidad de los micropueblos? ¿cuáles son las propuestas y oportunidades para mejorar las opciones de conseguir pueblos sostenibles?

\section{Aproximación al marco teórico y conceptual}

La expresión 'desarrollo rural' es de cariz polisémico ya que designa, al menos, un concepto teórico, una política pública y un proceso de cambios, así que, al estudiarlo, es necesario estar atentos "para distinguir entre sus medios y sus fines" o/y "para evitar interferencias y errores en la percepción e interpretación de dinámicas públicas y privadas” (Delgado Serrano, 2004, p. 297). Además, la sostenibilidad es un concepto polémico y con múltiples significados (Morén-Alegret y Wladyka, 2020), que ha ganado terreno en el ámbito rural a lo largo de las últimas décadas (Bruckmeier y Tovey, 2009). En este artículo, nos inspiramos en estudios como los del geógrafo William M. Adams (2006), en los que indica que se trata de un concepto que pone el énfasis en la interconexión, la continuidad en el tiempo y la unidad. En este sentido, la sostenibilidad siempre debería considerarse con sus dimensiones social, económica y ambiental, pues si se descuida cualquiera de ellas perdería su carácter holístico (Adams, 2006; MorénAlegret y Wladyka, 2020). La idea de sostenibilidad tiene más de 50 años, pues está relacionada con el nuevo mandato que fue adoptado en 1969 por la Unión International para la Conservación de la Naturaleza que llevó a que la sostenibilidad fuese un tema clave de la Conferencia de las Naciones Unidas para el Medio Humano de Estocolmo en 1972, entendida como concepto explícitamente acuñado para sugerir que es posible conseguir un desarrollo económico sin daño ambiental. En este sentido, la importancia del concepto está vinculada al tormentoso contexto sociopolítico de finales de las décadas de los años 1960 y los años 1970, cuando los movimientos ecologistas tomaron el

\footnotetext{
5 El topónimo oficial en catalán es Empordà, pero en castellano también se usa el topónimo Ampurdán.
} 
escenario público en algunos países occidentales para protestar, entre otros problemas, contra el daño ambiental causado por la contaminación industrial y el transporte de masas con combustibles fósiles (Morén-Alegret y Wladyka, 2020; Wall, 1999). En las siguientes décadas, el discurso mayoritario sobre desarrollo sostenible fue progresivamente canalizado a través de la Estrategia de Conservación Mundial (1980), el Informe Brundtland (1987) y la Conferencia de la ONU sobre Medio Ambiente y Desarrollo de Rio de Janeiro (1992), así como la planificación gubernamental y la implicación de líderes empresariales y de ONG (Adams, 2006; Morén-Alegret y Wladyka, 2020). De esta manera, el concepto 'sostenibilidad' es hijo del movimiento para la conservación de la naturaleza, pero ilustra el cambio de pasar de ser un movimiento a favor de la 'conservación de la naturaleza salvaje' (como si la 'naturaleza' estuviese separada de la vida humana) a ser un movimiento más amplio a favor de un planeta saludable, incluyendo a la población humana en el debate (Juniper, 2015; Morén-Alegret y Wladyka, 2020). En pocas palabras, se puede resaltar que hoy día, a pesar de las múltiples y contradictorias definiciones del concepto 'sostenibilidad', hay cierto consenso institucional en considerar que para conseguir la sostenibilidad es necesario que: 1) Personas, lugares y producción se alineen, procurando beneficios mutuos; 2) Se consideren al mismo nivel de importancia las tres dimensiones de la sostenibilidad - social, ambiental y económica - al tratar los desafíos que amenazan a personas, lugares y/o producciones; 3) Se tenga en cuenta la relevancia de la idea de 'integralidad', cubriendo tanto las necesidades materiales como las inmateriales (Espiña, 2011; Morén-Alegret y Wladyka, 2020).

Las ciudades y las áreas metropolitanas han adquirido una creciente importancia a nivel mundial (Glaeser, 2012; UN, 2014) y ello también ha afectado las narrativas sobre sostenibilidad que, a menudo, tienen un sesgo urbano (Portney, 2015; Rosenzweig et al., 2016), pero las áreas rurales y las pequeñas ciudades son igualmente relevantes para la sostenibilidad humana y planetaria (Morén-Alegret y Wladyka, 2020): ya en los años ochenta, el trascendente informe de la Comisión Brundtland propuso el desarrollo de estrategias explícitas para liberar de presión a las grandes áreas urbanas y construir pequeñas ciudades bien integradas con sus hinterlands rurales (The Brundtland Commission, 1987). Este informe es una de las publicaciones que sirvió de base histórica para la concreción de los 17 Objetivos de Desarrollo Sostenible (ODS) de la Agenda de la ONU que deberían alcanzarse en el año 2030 a nivel mundial ${ }^{6}$. Entre otros, el $2^{\circ}$ ODS pone atención en cuestiones rurales (Morén-Alegret et al., 2018): por ejemplo, la meta 2.a específicamente pide incrementar la inversión en infraestructuras rurales, incluyendo la ampliación de la cooperación internacional (UN, 2015). Además, en el

\footnotetext{
${ }^{6}$ Ver: https://sustainabledevelopment.un.org
} 
contexto de la UE, se ha resaltado la importancia de conseguir un desarrollo rural centrado en las personas y de promover sistemas para la producción sostenible de alimentos (EUROSTAT, 2016; 2017), mientras que la FAO (2018) ha indicado que uno de los desafíos clave que debe superar el desarrollo rural sostenible es la comunicación y diseminación de información (Morén-Alegret y Wladyka, 2020). En este sentido, en un informe publicado por la Organización Internacional para las Migraciones (IOM) sobre los ODS y las migraciones, se indicaba que faltan datos sobre el impacto de las políticas migratorias y los movimientos migratorios hacia y desde las áreas rurales (Mosler Vidal, 2018; Morén-Alegret y Wladyka, 2020). Así pues, este artículo contribuye a disminuir esa falta, estudiando algunas de las posibles relaciones entre inmigración, diversidad y sostenibilidad en áreas rurales (Scott et al., 2000).

La inmigración internacional se posiciona como una fuente de desarrollo local y comarcal, al detener (o al menos ralentizar) la despoblación en las áreas rurales (véase Bayona-i-Carrasco y Gil-Alonso, 2013; McAreavey y Argent, 2018). De hecho, la llegada de inmigrantes internacionales a las zonas rurales ha sido una parte fundamental de la reestructuración agrícola en Europa (Rye y Scott, 2018). Curiosamente, en la literatura científica, no se ha abordado lo suficiente el capital humano y social de la población inmigrante en áreas rurales (Halfacree, 2008), más allá de los inmigrantes internacionales que se insieren como trabajadores en la agricultura (Carson et al., 2018; Hedlund et al., 2017), aunque algunos estudios de caso europeos han observado recientemente que los emprendedores inmigrantes nacidos en el extranjero han sido claves en la creación e introducción de productos innovadores en nichos de mercado muy concretos poco explorados en estas zonas. Estos emprendedores, de esta forma, estimulan el desarrollo local y ayudan a fortalecer los valores relacionados con la sostenibilidad, la comunidad y el sentido de lugar (Yeasmin, 2016; Munkejord, 2017). Otros estudios sugieren que la población inmigrante internacional muestra una sensibilidad diferente a la hora de valorar los recursos locales, culturales o paisajísticos, que, de hecho, podría ser la razón de su llegada al "campo" (Bartoš et al., 2009; Iversen y Jacobsen, 2017). De esta forma, estos inmigrantes internacionales cuentan con el potencial de imaginar la cultura local, el paisaje y la naturaleza como posibles productos turísticos, así como para reconocer oportunidades de negocio que la población 'local', tanto oriundos de zonas rurales como inmigrantes internos, podría obviar (Bosworth y Farrell, 2011; Mattsson y Cassel, 2019).

Entre las migraciones internacionales hacia áreas rurales destacan los llamados 'lifestyle immigrants', un número relevante de los cuales son inmigrantes emprendedores o/y cualificados (Kordel et al., 2018; Mendoza et al., 2020). La elección 
de pueblos o aldeas como lugares de destino de ese tipo de migrantes 'por estilo de vida' no es casual, pues ya hace algunas décadas que lo rural pasó a ser considerado un constructo social y un estilo de vida (Camarero, 1996; Cloke y Milbourne, 1992). En este contexto, ciertamente, una mayor variedad de datos sobre inmigración internacional puede ayudar a prevenir dificultades innecesarias en diversos territorios y, en especial, afrontar los desafíos que emergen en contextos rurales (Morén-Alegret y Wladyka, 2020). Así pues, de cara a contribuir a cubrir esas lagunas de información, este artículo ofrece datos e información cualitativa sobre la percepción que informantes claves seleccionados entre la población inmigrante nacida en el extranjero asentada en pueblos pequeños del Alt Empordà tiene de los principales desafíos para la sostenibilidad rural. En este sentido, se debería superar el viejo estereotipo del campo como un lugar sólo habitado por personas nacidas en el lugar de residencia. En los pueblos del Alt Empordà y en otros lugares rurales de Europa, desde hace años, una parte importante de la población residente es inmigrante internacional o de origen inmigrante, por lo que se hace necesario dar voz y escuchar sus experiencias o percepciones de cara a comprender mejor los cambios recientes y la situación actual de los pueblos (Morén-Alegret y Wladyka, 2020; Woods, 2016), lo cual podría repercutir en una mayor y variada información de cara a mejorar las políticas públicas tanto a nivel local como a otras escalas territoriales (Delgado Serrano, 2004).

\section{Metodología, métodos, fuentes y área de estudio}

\subsection{Metodología, métodos y fuentes}

Este artículo se basa en un trabajo de campo realizado durante 2019 e inicios de 2020 en el marco de un proyecto de investigación más amplio que consistió en dos principales estudios de caso en Cataluña: uno centrado en el Alt Empordà (nordeste de la provincia de Girona), objeto de este artículo, y otro en los Pirineos de la provincia de Lleida, tratado en otras publicaciones. Para el caso del Alt Empordà, se realizaron 17 entrevistas semiestructuradas con inmigrantes internacionales (véase Tabla 1 donde se detallan las características sociodemográficas de estas personas) y 25 entrevistas con informantes clave nacidos en España y relacionados con la provincia de Girona (particularmente, emprendedores locales y/o representantes políticos, de asociaciones de empresarios, ONG u otras entidades sociales, económicas y ambientales). El objetivo no era obtener una muestra representativa, sino conseguir una variedad de entrevistas que sean cualitativamente relevantes y originales. En este sentido, hay que tener en cuenta que, como se detalla más adelante, a pesar de algunos porcentajes relativamente elevados en algunos municipios, la cantidad de personas inmigradas residentes en pueblos con menos de 500 habitantes es relativamente pequeña, se trata de personas dispersas por 
el territorio y, como personal investigador universitario, acceder a ellas es más difícil y costoso que en estudios sobre pueblos más grandes o ciudades. Además, durante el proyecto se realizaron otras 19 entrevistas semiestructuradas a diversos informantes clave relacionados con la inmigración y/o el desarrollo rural a nivel de Cataluña y/o España en su conjunto que sirvieron para poner mejor en contexto las dos principales áreas de estudio7.

\section{Tabla 1. Perfil de los inmigrantes nacidos en el extranjero}

\begin{tabular}{|c|c|c|c|c|c|}
\hline Núm. & Sexo & Edad & País de nacimiento & $\begin{array}{l}\text { Años en } \\
\text { España }\end{array}$ & $\begin{array}{l}\text { Relación con la actividad y/o } \\
\text { ocupación }\end{array}$ \\
\hline 1 & $\mathrm{H}$ & 66 & Alemania & 39 & $\begin{array}{l}\text { Empresario de turismo rural / } \\
\text { jubilado }\end{array}$ \\
\hline 2 & $\mathrm{M}$ & 71 & Alemania & 19 & Jubilada \\
\hline 3 & $\mathrm{M}$ & 48 & Italia & 12 & $\begin{array}{l}\text { Empresaria agrícola y de } \\
\text { turismo rural }\end{array}$ \\
\hline 4 & $\mathrm{H}$ & 58 & Italia & 2 & Empresario de turismo rural \\
\hline 5 & $\mathrm{H}$ & 68 & Países Bajos & $\begin{array}{l}20 \\
\text { (temporadas) }\end{array}$ & $\begin{array}{l}\text { Trabajador autónomo/ } \\
\text { jubilado }\end{array}$ \\
\hline 6 & $\mathrm{M}$ & 62 & Nicaragua & 2 & Jubilada \\
\hline 7 & $\mathrm{H}$ & 62 & Suiza & 2 & Jubilado \\
\hline 8 & $\mathrm{M}$ & 40 & Gran Bretaña & 15 & Trabajadora autónoma \\
\hline 9 & $\mathrm{H}$ & 44 & Argentina & 3 & Asalariado. Médico \\
\hline 10 & M & 48 & Países Bajos & 15 & Trabajadora autónoma \\
\hline 11 & M & 58 & Bélgica & 18 & Trabajadora autónoma \\
\hline 12 & $\mathrm{H}$ & 65 & Alemania & 33 & $\begin{array}{l}\text { Trabajador autónomo / } \\
\text { jubilado }\end{array}$ \\
\hline 13 & $\mathrm{H}$ & 54 & Marruecos & 29 & $\begin{array}{l}\text { Asalariado. Trabajador } \\
\text { mantenimiento }\end{array}$ \\
\hline 14 & M & 58 & Gran Bretaña & 30 & Trabajadora autónoma \\
\hline 15 & M & 28 & Países Bajos & 2 & Empresaria agrícola \\
\hline 16 & $\mathrm{M}$ & 32 & Canadá & 7 & Hogar \\
\hline 17 & $\mathrm{M}$ & 41 & Gran Bretaña & 8 & Hogar \\
\hline
\end{tabular}

Fuente: Elaboración propia a partir de trabajo de campo (mayo 2019-febrero 2020).

Este artículo se centra en las percepciones y experiencias de las personas nacidas en el extranjero y que han vivido como mínimo más de dos años en micropueblos del Alt Empordà (algunas de ellas han residido durante décadas). Las personas entrevistadas fueron seleccionadas a través de los contactos previos del equipo de investigación en la

\footnotetext{
7 También se realizaron 15 entrevistas semi-estructuradas con inmigrantes internacionales vinculados a micropueblos del Pirineo de la provincia de Lleida, así como otras 40 entrevistas con informantes clave nacidos en España pertenecientes a diversas organizaciones de esas comarcas leridanas (algunos con doble nacionalidad). Por tanto, durante el proyecto, en total se realizaron en la CCAA de Cataluña 116 entrevistas semi-estructuradas a diversos informantes clave. Adicionalmente, en ese proyecto se realizaron 16 entrevistas con varios informantes clave de los Pirineos Orientales franceses.
} 
Morén-Alegret, R. y Mendoza, C.

comarca y, para evitar sesgos, a través de varios ayuntamientos e instituciones, así como a partir de la técnica de la bola de nieve. Se buscó un cierto equilibrio en los entrevistados con respecto a sus características sociodemográficas y así se entrevistaron hombres y mujeres en una relación 7:10, priorizando la voz de las mujeres, y personas de diferentes grupos de edad, tanto menores como mayores de 55 años (8/7). Las entrevistas tuvieron una duración media de aproximadamente una hora, se realizaron en catalán, castellano o inglés (según la preferencia del entrevistado) y el lugar fue elegido por la persona entrevistada. El material cualitativo se revisó a través del método de análisis de contenido en varias fases (Mendoza et al., 2020): 1) los códigos se definieron de acuerdo con las temáticas surgidas durante las entrevistas; 2) se etiquetaron las entrevistas y se agruparon los extractos de las mismas en diferentes temas; 3) se realizó una lectura y análisis sistemáticos de esta información para permitir la abstracción, seleccionando citas pertinentes para ilustrar las principales líneas de análisis.

\subsection{Aproximación al área de estudio}

Para el conjunto de Cataluña, los 337 municipios con menos de 500 habitantes (micropueblos) representan más de un tercio del conjunto de municipios (36\%) y del conjunto de la superficie territorial, pero solo el 1,1\% de la población total de la región (Instituto Nacional de Estadística, 2019). La presencia de personas nacidas en el extranjero en los micropueblos de Cataluña es muy variada. Observamos desde municipios cuya presencia es nula o casi testimonial ( 1 ó 2 personas nacidas en el extranjero) hasta municipios que presentan porcentajes parecidos a los de algunas grandes áreas urbanas catalanas y españolas (alrededor del 20\% de la población o incluso cifras superiores que pueden llegar a acercarse al 30\% en algunos pocos casos). Territorialmente, los porcentajes más elevados de población nacida en el extranjero (>20\%) se encuentran en comarcas de costa, como el Alt Empordà (Figura 1), y en algunas zonas del Pirineo cercanas a estaciones de esquí (Mendoza et al., 2020; Romagosa et al., 2020). 


\section{Figura 1. Localización de los micropueblos del Alt Empordà, de los principales núcleos urbanos y de las principales vías de transporte}

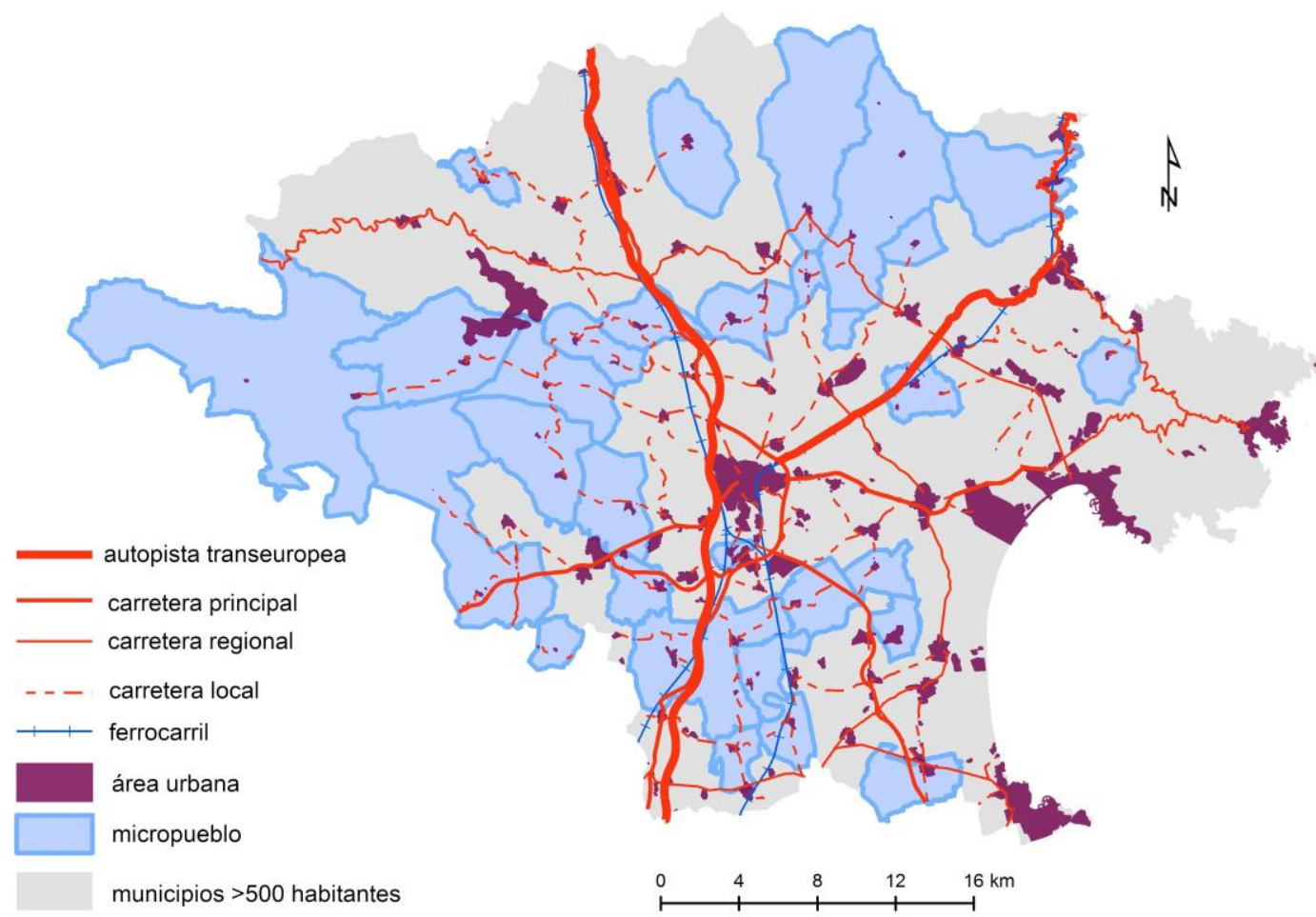

Fuente: Proyecto de investigación HAMLETS (2019). Autora del mapa: Laia Mojica.

El Alt Empordà es una comarca que está bañada por el mar Mediterráneo en el este y que limita con Francia en el norte, destacando por ser la comarca con más micropueblos de Cataluña: veintinueve de sus municipios (el 40\% del total) tienen menos de 500 habitantes empadronados (Instituto Nacional de Estadística, 2019). En el año 1990 esos veintinueve municipios sumaban 6.278 habitantes, pero en 2018 sumaban 7.755 habitantes, en 2019 llegaron a los 7813 habitantes y en 2020 ascendieron ligeramente hasta tener 7835 habitantes en total, lo que representa el 5,49\% de la población comarcal (Instituto Nacional de Estadística, 2019; Institut d'Estadística de Catalunya, 2020a). Sin embargo, a nivel municipal, como se puede apreciar en la Tabla 2, a lo largo de los últimos años la evolución poblacional ha sido desigual y, de hecho, en algunos municipios la población empadronada ha disminuido, fluctuado o está relativamente estancada. No hay un patrón territorial claro. Así, encontramos que, en los últimos años, se dan descensos de empadronados tanto en el único micropueblo ubicado en el litoral (Colera) como en municipios montañosos de interior como La Vajol (ambos con relativamente altos porcentajes de población inmigrante internacional), mientras que ganan población municipios casi litorales como La Selva de Mar (con relativamente poca 
población inmigrante internacional) o Vilamacolum ${ }^{8}$ y municipios interiores al pie de las montañas, como Sant Llorenç de la Muga, con un relativamente alto porcentaje de población nacida en el extranjero y con nacionalidad extranjera.

Tabla 2. Evolución de la población empadronada en micropueblos del Alt Empordà (1990-2020) y porcentaje de población extranjera y nacida en el extranjero (2020)

\begin{tabular}{|c|c|c|c|c|c|c|c|}
\hline $\begin{array}{l}\text { Municipios con } \\
\text { menos de } 500 \\
\text { habitantes en } \\
2020\end{array}$ & $\begin{array}{l}\text { Total } \\
\text { población } \\
\text { en } 2020\end{array}$ & $\begin{array}{l}\text { Total } \\
\text { población } \\
\text { en } 2019\end{array}$ & $\begin{array}{l}\text { Total } \\
\text { población } \\
\text { en } 2009\end{array}$ & $\begin{array}{l}\text { Total } \\
\text { población } \\
\text { en } 1990\end{array}$ & $\begin{array}{l}\text { \% } \\
\text { población } \\
\text { nacida en } \\
\text { el } \\
\text { extranjero } \\
\text { en } 2020\end{array}$ & $\begin{array}{l}\text { \% población } \\
\text { nacionalidad } \\
\text { extranjera } \\
\text { en } 2020\end{array}$ & $\begin{array}{l}\% \\
\text { población } \\
\text { nacida en } \\
\text { el } \\
\text { extranjero } \\
\text { en } 2018\end{array}$ \\
\hline Albanyà & 155 & 157 & 152 & 108 & $13,55 \%$ & $12,90 \%$ & $11,51 \%$ \\
\hline Biure & 241 & 232 & 243 & 273 & $14,52 \%$ & $12,86 \%$ & $11,76 \%$ \\
\hline $\begin{array}{l}\text { Boadella i les } \\
\text { Escaules }\end{array}$ & 272 & 252 & 241 & 241 & $11,76 \%$ & $9,56 \%$ & $11,52 \%$ \\
\hline Cabanelles & 267 & 279 & 236 & 245 & $23,59 \%$ & $20,60 \%$ & $19,78 \%$ \\
\hline Cantallops & 309 & 313 & 319 & 256 & $21,35 \%$ & $16,83 \%$ & $18,53 \%$ \\
\hline Cistella & 282 & 282 & 238 & 209 & $12,41 \%$ & $9,93 \%$ & $12,67 \%$ \\
\hline Colera & 445 & 448 & 573 & 429 & $18,87 \%$ & $15,06 \%$ & $18,92 \%$ \\
\hline Espolla & 412 & 416 & 404 & 399 & $13,59 \%$ & $9,47 \%$ & $14,59 \%$ \\
\hline Garrigàs & 451 & 437 & 395 & 324 & $10,42 \%$ & $8,43 \%$ & $10,02 \%$ \\
\hline Masarac & 288 & 288 & 265 & 257 & $22,22 \%$ & $21,53 \%$ & $16,91 \%$ \\
\hline $\begin{array}{l}\text { Mollet de } \\
\text { Peralada }\end{array}$ & 198 & 189 & 174 & 164 & $11,61 \%$ & $8,59 \%$ & $11,05 \%$ \\
\hline Ordis & 361 & 371 & 372 & 298 & $7,75 \%$ & $6,65 \%$ & $12,04 \%$ \\
\hline $\begin{array}{l}\text { Palau de } \\
\text { Santa Eulàlia }\end{array}$ & 90 & 91 & 112 & 75 & $6,66 \%$ & $4,44 \%$ & $8,42 \%$ \\
\hline $\begin{array}{l}\text { Pedret i } \\
\text { Marzà }\end{array}$ & 191 & 198 & 160 & 129 & $14,13 \%$ & $8,90 \%$ & $14,36 \%$ \\
\hline Pontós & 260 & 266 & 238 & 204 & $14,23 \%$ & $11,92 \%$ & $12,96 \%$ \\
\hline Rabós & 184 & 178 & 217 & 151 & $16,30 \%$ & $14,67 \%$ & $15,64 \%$ \\
\hline Riumors & 246 & 258 & 233 & 202 & $14,22 \%$ & $12,60 \%$ & $16,35 \%$ \\
\hline $\begin{array}{l}\text { Sant Llorenç } \\
\text { de la Muga }\end{array}$ & 265 & 264 & 213 & 160 & $23,77 \%$ & $23,02 \%$ & $22,31 \%$ \\
\hline Sant Mori & 166 & 177 & 180 & 142 & $21,68 \%$ & $12,05 \%$ & $24,86 \%$ \\
\hline $\begin{array}{l}\text { Santa Llogaia } \\
\text { d'Àlguema }\end{array}$ & 368 & 370 & 335 & 307 & $6,52 \%$ & $3,26 \%$ & $6,06 \%$ \\
\hline $\begin{array}{l}\text { Selva de Mar, } \\
\text { La }\end{array}$ & 195 & 196 & 226 & 160 & $12,30 \%$ & $6,67 \%$ & $9,63 \%$ \\
\hline Siurana & 171 & 168 & 206 & 175 & $9,35 \%$ & $8,77 \%$ & $9,26 \%$ \\
\hline Terrades & 338 & 329 & 301 & 179 & $11,24 \%$ & $8,88 \%$ & $10,51 \%$ \\
\hline Vajol, La & 89 & 89 & 98 & 60 & $30,34 \%$ & $23,60 \%$ & $22,35 \%$ \\
\hline Viladamat & 458 & 468 & 466 & 365 & $10,04 \%$ & $8,08 \%$ & $11,80 \%$ \\
\hline Vilamacolum & 377 & 348 & 322 & 264 & $29,97 \%$ & $31,30 \%$ & $22,12 \%$ \\
\hline Vilamaniscle & 212 & 200 & 169 & 122 & $19,81 \%$ & $14,62 \%$ & $21,15 \%$ \\
\hline Vilanant & 386 & 392 & 356 & 277 & $10,10 \%$ & $9,07 \%$ & $11,28 \%$ \\
\hline Vilaür & 158 & 157 & 140 & 103 & $14,55 \%$ & $13,29 \%$ & $12,24 \%$ \\
\hline Total & 7835 & 7813 & 7584 & 6278 & $15,41 \%$ & $12,67 \%$ & $14,50 \%$ \\
\hline
\end{tabular}

Fuente: elaboración propia a partir de datos del Institut d'Estadística de Catalunya (2021), del Padrón a 1 de enero.

\footnotetext{
8 Vilamacolum es un municipio con un mayor porcentaje de población extranjera que nacidos en el extranjero debido a la mayor presencia de población de origen africano, población a la que habitualmente cuesta más conseguir la nacionalidad española que a la población de origen europeo o latinoamericano (estas últimas son las más habituales inmigraciones en la mayoría de micropueblos del Alt Empordà).
} 
Otra característica comarcal es que, como también se puede apreciar en la Tabla 2, en todos los micropueblos del Alt Empordà reside población nacida en el extranjero, mientras que hay comarcas de la provincia de Lleida y del interior de Tarragona donde hay varios micropueblos sin ningún inmigrante internacional. Según los datos del padrón continuo de población, el 44,4\% de la población de los micropueblos no es nacida en el mismo municipio en el que reside y resalta, en este sentido, el 15,3\% de inmigrantes internacionales (Instituto Nacional de Estadística, 2019). De estos últimos que suman un total de 1.190 residentes en los micropueblos del Alt Empordà, 493 (4 de cada 10) son originarios de países pertenecientes a la UE-25, es decir, de países cuyo tipo de inmigrante mayoritario suele coincidir con el perfil del inmigrante por estilo de vida (asociado al turismo residencial y al modelo de emprendedor turístico, cultural y/o agroecológico) que suele tender a la rural-filia o amor por lo rural (Morén-Alegret, 2008). Los que más abundan son los nacidos en Francia (204), seguidos de los procedentes del Reino Unido (67) y Alemania (52). Este perfil de inmigrantes supone el 6,4\% de la población de los micropueblos de la comarca, siendo este porcentaje tres veces más elevado que la media para el conjunto de los micropueblos de Cataluña, el 2,2\% (Mendoza et al., 2020; Romagosa et al., 2020). Estos datos, en todo caso, sugieren una posible dinámica demográfica positiva en micropueblos de la comarca que, por otro lado, irían en la línea de lo apuntado por otros autores en otras áreas rurales de España (p. ej., Collantes et al., 2010; Collantes et al., 2014) y que quizá sugieren un nuevo ciclo de crecimiento demográfico más amplio en algunas partes de la España rural, quebrando así una visión un tanto catastrofista que, en ocasiones, se transmite desde algunos medios de comunicación.

Sin embargo, a la luz de los datos disponibles para los micropueblos del Alt Empordà, la llegada de inmigración extranjera parece insuficiente para superar otro problema de largo alcance que afecta algunas áreas rurales españolas: la masculinización de la población de algunos pueblos. Como se puede observar en la Tabla 3, en conjunto se puede apreciar que en 2020 la mayor parte tanto de la población con nacionalidad española como de la población extranjera empadronada en los micropueblos del Alt Empordà es masculina.

Tabla 3. Población empadronada en 2020 en micropueblos del Alt Empordà, por sexo y nacionalidad (española/extranjera)

\begin{tabular}{|l|l|l|l|l|l|}
\hline $\begin{array}{l}\text { Municipios } \\
\text { con menos } \\
\text { de 5oo } \\
\text { habitantes } \\
\text { en 2020 }\end{array}$ & $\begin{array}{l}\text { Hombres } \\
\text { con } \\
\text { nacionalidad } \\
\text { española }\end{array}$ & $\begin{array}{l}\text { Hombres } \\
\text { con } \\
\text { nacionalidad } \\
\text { extranjera }\end{array}$ & $\begin{array}{l}\text { Mujeres con } \\
\text { nacionalidad } \\
\text { española }\end{array}$ & $\begin{array}{l}\text { Mujeres con } \\
\text { nacionalidad } \\
\text { extranjera }\end{array}$ & $\begin{array}{l}\text { Total } \\
\text { población } \\
\text { en 2020 }\end{array}$ \\
\hline Albanyà & 71 & 8 & 64 & 12 & 155 \\
\hline Biure & 111 & 14 & 99 & 17 & 241 \\
\hline
\end{tabular}




\begin{tabular}{|c|c|c|c|c|c|}
\hline $\begin{array}{l}\text { Boadella i les } \\
\text { Escaules }\end{array}$ & 124 & 13 & 122 & 13 & 272 \\
\hline Cabanelles & 123 & 27 & 89 & 28 & 267 \\
\hline Cantallops & 128 & 25 & 129 & 27 & 309 \\
\hline Cistella & 123 & 14 & 131 & 14 & 282 \\
\hline Colera & 190 & 27 & 188 & 40 & 445 \\
\hline Espolla & 183 & 21 & 190 & 18 & 412 \\
\hline Garrigàs & 217 & 17 & 196 & 21 & 451 \\
\hline Masarac & 110 & 40 & 116 & 22 & 288 \\
\hline $\begin{array}{l}\text { Mollet de } \\
\text { Peralada }\end{array}$ & 94 & 10 & 87 & 7 & 198 \\
\hline Ordis & 179 & 14 & 158 & 10 & 361 \\
\hline $\begin{array}{l}\text { Palau de } \\
\text { Santa Eulàlia }\end{array}$ & 50 & 1 & 36 & 3 & 90 \\
\hline $\begin{array}{l}\text { Pedret i } \\
\text { Marzà }\end{array}$ & 86 & 11 & 88 & 6 & 191 \\
\hline Pontós & 126 & 15 & 103 & 16 & 260 \\
\hline Rabós & 77 & 15 & 80 & 12 & 184 \\
\hline Riumors & 100 & 21 & 115 & 10 & 246 \\
\hline $\begin{array}{l}\text { Sant Llorenç } \\
\text { de la Muga }\end{array}$ & 104 & 30 & 100 & 31 & 265 \\
\hline Sant Mori & 75 & 9 & 71 & 11 & 166 \\
\hline $\begin{array}{l}\text { Santa Llogaia } \\
\text { d'Àlguema }\end{array}$ & 181 & 8 & 175 & 4 & 368 \\
\hline $\begin{array}{l}\text { Selva de Mar, } \\
\text { La }\end{array}$ & 103 & 2 & 79 & 11 & 195 \\
\hline Siurana & 73 & 9 & 83 & 6 & 171 \\
\hline Terrades & 153 & 13 & 155 & 17 & 338 \\
\hline Vajol, La & 37 & 14 & 31 & 7 & 89 \\
\hline Viladamat & 215 & 17 & 206 & 20 & 458 \\
\hline Vilamacolum & 126 & 85 & 133 & 33 & 377 \\
\hline Vilamaniscle & 104 & 17 & 77 & 14 & 212 \\
\hline Vilanant & 174 & 20 & 177 & 15 & 386 \\
\hline Vilaür & 70 & 10 & 67 & 11 & 158 \\
\hline Total & $\mathbf{3 5 0 7}$ & 527 & 3345 & 456 & 7835 \\
\hline
\end{tabular}

Fuente: elaboración propia a partir de datos del Institut d'Estadística de Catalunya (2021),

Padrón a 1 de enero.

Aun así, como también se puede apreciar en la Tabla 3, en casi la mitad de los micropueblos de esa comarca (14) la población extranjera es mayoritariamente femenina. Es interesante destacar que muchos de estos catorce municipios tienen una población española masculinizada con lo que en ellos sí que la llegada de población extranjera mayoritariamente femenina contribuye (con diversas intensidades) a un mayor equilibrio poblacional entre mujeres y hombres a nivel municipal, destacando pueblos turísticos como Colera y La Selva de Mar. En cambio, por otro lado, en municipios como Vilamacolum y Riumors, donde hay más población española femenina que masculina y la economía está más diversificada (incluyendo un relevante sector primario, entre otros9), la población extranjera es mayoritariamente masculina, con lo

\footnotetext{
9 Ver, por ejemplo, la importancia de los silos de cereales: https://www.solventa6.com/noves-sitges-ambcapacitat-per-3-200-tm-de-cereals-a-vilamacolum-girona/?lang=es
} 
que también contribuye de alguna manera a minimizar otro posible tipo de desequilibrio por sexos.

Por otro lado, en relación al desequilibrio por grupos de edad causante del conocido envejecimiento rural, como se puede apreciar en la Tabla 4, en general, el empadronamiento en los micropueblos del Alt Empordà de una población extranjera con un cierto equilibrio entre menores de 16 años y mayores de 65 años es insuficiente para compensar el importante envejecimiento de la población con nacionalidad española. Sin embargo, en algunos municipios como Vilamacolum o Espolla (donde hay una economía diversificada que incluye un relevante sector primario) sí que se produce un cierto rejuvenecimiento gracias a la población extranjera, lo que contrasta con un municipio turístico como Colera, donde la población extranjera es mayoritariamente de 65 y más años.

Tabla 4. Población empadronada en 2016 por nacionalidad y grupos de edad

\begin{tabular}{|c|c|c|c|c|c|c|c|}
\hline & $\begin{array}{l}\text { Población } \\
\text { total en } 2016\end{array}$ & $\begin{array}{l}\text { Población } \\
\text { española } \\
2016 \\
\end{array}$ & & & $\begin{array}{l}\text { Población } \\
\text { extranjera } \\
2016 \\
\end{array}$ & & \\
\hline $\begin{array}{l}\text { Municipios } \\
\text { con menos } \\
\text { de } 500 \\
\text { habitantes } \\
\text { en } 2020\end{array}$ & $\begin{array}{l}\text { Todas las } \\
\text { edades y } \\
\text { nacionalidades }\end{array}$ & $\begin{array}{l}\text { Menores } \\
\text { de } 16 \text { años }\end{array}$ & $\begin{array}{l}\text { De } 16 \\
\text { a } 64 \\
\text { años }\end{array}$ & $\begin{array}{l}\text { De } 65 \text { y } \\
\text { más } \\
\text { años }\end{array}$ & $\begin{array}{l}\text { Menores de } \\
16 \text { años }\end{array}$ & $\begin{array}{l}\text { De } 16 \text { a } \\
64 \text { años }\end{array}$ & $\begin{array}{l}\text { De } 65 \text { y } \\
\text { más años }\end{array}$ \\
\hline Albanyà & 147 & 30 & 87 & 20 & 1 & 8 & 1 \\
\hline Biure & 233 & 27 & 130 & 56 & $\mathrm{O}$ & 15 & 5 \\
\hline $\begin{array}{l}\text { Boadella i les } \\
\text { Escaules }\end{array}$ & 266 & 35 & 150 & 52 & 3 & 25 & 1 \\
\hline Cabanelles & 257 & 41 & 119 & 51 & 5 & 33 & 8 \\
\hline Cantallops & 317 & 44 & 153 & 67 & 4 & 39 & 10 \\
\hline Cistella & 293 & 45 & 161 & 58 & 3 & 21 & 5 \\
\hline Colera & 522 & 46 & 264 & 111 & 9 & 63 & 29 \\
\hline Espolla & 421 & 45 & 215 & 112 & 10 & 36 & 3 \\
\hline Garrigàs & 435 & 64 & 255 & 79 & 2 & 30 & 5 \\
\hline Masarac & 289 & 37 & 143 & 55 & 6 & 47 & 1 \\
\hline $\begin{array}{l}\text { Mollet de } \\
\text { Peralada }\end{array}$ & 180 & 29 & 85 & 56 & 1 & 7 & 2 \\
\hline Ordis & 377 & 58 & 215 & 71 & 4 & 27 & 2 \\
\hline $\begin{array}{l}\text { Palau de } \\
\text { Santa Eulàlia }\end{array}$ & 90 & 10 & 55 & 18 & 1 & 5 & 1 \\
\hline $\begin{array}{l}\text { Pedret i } \\
\text { Marzà }\end{array}$ & 180 & 33 & 103 & 31 & $\mathrm{O}$ & 13 & $\mathrm{O}$ \\
\hline Pontós & 234 & 30 & 133 & 53 & 2 & 15 & 1 \\
\hline Rabós & 188 & 18 & 88 & 55 & 4 & 19 & 4 \\
\hline Riumors & 255 & 37 & 129 & 51 & 3 & 29 & 6 \\
\hline $\begin{array}{l}\text { Sant Llorenç } \\
\text { de la Muga }\end{array}$ & 247 & 29 & 117 & 48 & 9 & 37 & 7 \\
\hline Sant Mori & 176 & 25 & 86 & 32 & 4 & 27 & 2 \\
\hline $\begin{array}{l}\text { Santa } \\
\text { Llogaia } \\
\text { d'Àlguema }\end{array}$ & 343 & 60 & 220 & 45 & 3 & 15 & O \\
\hline
\end{tabular}




\begin{tabular}{|l|l|l|l|l|l|l|l|}
$\begin{array}{l}\text { Selva de } \\
\text { Mar, La }\end{array}$ & 188 & 13 & 123 & 45 & 0 & 7 & 0 \\
\hline Siurana & 155 & 19 & 84 & 39 & 2 & 9 & 2 \\
\hline Terrades & 285 & 40 & 161 & 57 & 1 & 23 & 3 \\
\hline Vajol, La & 83 & 4 & 49 & 13 & 1 & 14 & 2 \\
\hline Viladamat & 466 & 60 & 259 & 97 & 6 & 37 & 7 \\
\hline Vilamacolum & 320 & 39 & 153 & 66 & 15 & 47 & 0 \\
\hline Vilamaniscle & 202 & 33 & 101 & 30 & 7 & 30 & 1 \\
\hline Vilanant & 405 & 68 & 230 & 67 & 5 & 32 & 3 \\
\hline Vilaür & $\mathbf{1 5 6}$ & 34 & 75 & 31 & $\mathbf{2}$ & $\mathbf{1 3}$ & $\mathbf{1}$ \\
\hline Total & $\mathbf{7 7 1 0}$ & $\mathbf{1 0 5 3}$ & $\mathbf{4 1 4 3}$ & $\mathbf{1 5 6 6}$ & $\mathbf{1 1 3}$ & $\mathbf{7 2 3}$ & $\mathbf{1 1 2}$ \\
\hline
\end{tabular}

Fuente: Instituto Nacional de Estadística (2019), a partir de datos del Padrón municipal a 1 de enero.

El Alt Empordà pertenece a una de las provincias más ricas de España, aunque es una de las comarcas catalanas con más desigualdad de renta y, durante los últimos años, la provincia de Girona en general ha perdido importancia económica relativa debido al mayor crecimiento de otros territorios peninsulares (Garriga, 2020). En varios municipios ampurdaneses, el desarrollo local depende de las inversiones extranjeras en bienes raíces, del gasto turístico y de empresas locales creadas por inmigrantes (Mendoza et al., 2020; Morén-Alegret y Wladyka, 2020). Según el mapa de dinamismo socioeconómico (2018-2019), elaborado por el Observatorio del Mundo Rural del Departamento de Agricultura, Ganadería y Pesca del gobierno catalán (DARPA, 2020), entre los municipios más dinámicos de Catalunya se encuentran micropueblos del Alt Empordà como Albanyà, Cabanelles, Cantallops, Cistella o Rabós ${ }^{10}$. Además, la comarca posee como capital una ciudad de mediano tamaño que ofrece una variedad notable de servicios y equipamientos (Figueres), una Costa Brava fuertemente especializada en turismo que incluye algunas pequeñas ciudades (Roses, Castelló d'Empúries), y una zona interior relativamente amplia y rural, encuadrada por la cordillera de la Albera (la parte baja de los Pirineos al llegar al Mediterráneo) y compuesta por pequeños pueblos cuyas actividades económicas han pasado progresivamente de la agricultura a los servicios. En concreto, según los últimos datos disponibles del Censo Agrario, la superficie agraria utilizada (SAU) disminuyó en un 25\% en diez años, de 85.676 ha. en 1999 a 63.835 en 2009 en la comarca (Institut d'Estadística de Catalunya, 2020b). La población ocupada en la agricultura, por su parte, también se redujo hace unos años, aunque en menor medida: pasó del 8,4\% en 1996 al 5,6\% en 2011, de acuerdo con los datos del Censo de Población y Vivienda, aunque esta disminución se debería contextualizar en el aumento de la población ocupada para el conjunto de la comarca (Institut d'Estadística de Catalunya, 2020a, Mendoza et al., 2020). Sin embargo, después de la crisis de 20082012, entre 2013 y 2018 la población ocupada en el Alt Empordà creció en todos los

\footnotetext{
${ }^{10}$ Aunque también se ubican en la comarca del Alt Empordà unos pocos micropueblos considerados como poco dinámicos socioeconómicamente, como La Vajol o Colera.
} 
sectores, incluida la agricultura con un ligero aumento (Garriga, 2020). Además, es interesante tener en cuenta que, durante la última década, el Alt Empordà es la comarca de la provincia de Girona con un mayor y creciente porcentaje del PIB dedicado al sector agrario: pasó del 3,91\% en 2008 al 6,30\% en 2018 (Garriga, 2020). Entre otras actividades agropecuarias, muchas de ellas vinculadas a micropueblos, en el Alt Empordà se puede destacar la ganadería, tanto intensiva como extensiva (en marzo de 2021 ${ }^{11}$, había 289 explotaciones porcinas, 244 de équidos, 214 bovinas, 114 ovinas y 108 de gallinas o pollos, entre otros tipos de explotaciones) y, por otro lado, se puede destacar la viticultura, pues el Alt Empordà es una comarca que desde 1975 cuenta con Denominación de Origen (D.O.) compartida con la comarca vecina de El Baix Empordà ${ }^{12}$, una actividad agraria incipientemente vinculada al turismo rural (Romagosa et al., 2020). Por último, el Alt Empordà, además de estar ubicado a relativa poca distancia de los aeropuertos de Girona y de Perpiñán, está bien comunicado por carretera y tren tanto con el Área Metropolitana de Barcelona y el resto de España, como con el sur de Francia y el resto de Europa. A ello se puede añadir también la creciente importancia del puerto marítimo de Roses como puerta de entrada a la comarca, por ejemplo, gracias a la llegada de cruceros turísticos ${ }^{13}$, así como, desde hace años, lugar de iniciativas que combinan la preservación del sector pesquero y el turismo cultural o ecológico' ${ }^{14}$.

\section{Inmigración internacional y sostenibilidad: retos y oportunidades en el Alt Empordà rural}

Siguiendo los principios de la investigación cualitativa, en esta sección se da voz (Ragin, 1994) a personas entrevistadas que habitualmente están fuera del foco de atención pública en relación a temáticas que afectan a la población rural en general. En los breves fragmentos de entrevistas ${ }^{15}$ que se ofrecen a continuación se indica un código para el ámbito de la(s) principal(es) actividad(es) de la persona inmigrante (SC para social; EC para económico; AMB para ambiental), su edad en años, el país de nacimiento y el sexo. Por motivos de claridad expositiva, inspirándonos en Ely et al. (1997) y

\footnotetext{
${ }^{11}$ Ver: http://agricultura.gencat.cat/ca/serveis/registres-oficials/ramaderia-sanitat-animal/registreexplotacions-ramaderes/visor-interactiu-rer/

${ }^{12}$ Como se indica en la página web de la D.O.: "la aprobación por parte del Ministerio de Agricultura, el año 1975, de la Denominación de Origen Ampurdán-Costa Brava para los vinos ampurdaneses (Orden de 19 de mayo de 1975, publicada en el BOE núm. 153, de 27 de junio) representó el reconocimiento oficial de que estos vinos han logrado, después de muchos años, unos niveles de prestigio y calidad suficientes para competir en el mercado con vinos de otras procedencias" (https://www.doemporda.cat/es/el-consejoregulador.html). La D.O. tiene su sede en Figueres y desde 2006 la D.O. pasó a denominarse 'Empordà'.

13 Ver: https://ports.gencat.cat/es/cruceros-de-roses/

14 Ver: https://www.abc.es/economia/20130717/abci-pescadores-roses-experiencia201307161708.html?ref=https\%3A\%2F\%2Fwww.google.com\%2F

15 En esta sección mostramos resultados del análisis con una selección ilustrativa de breves fragmentos de entrevistas, inspirados por lo que sugirió William Shakespeare: "speak, breathe, discuss; brief, short, quick, snap”.
} 
siguiendo publicaciones previas (p. ej. Morén-Alegret y Wladyka, 2020), hemos estructurado la presentación de ejemplos ilustrativos de algunos resultados del análisis cualitativo de acuerdo a una de las principales dimensiones de la sostenibilidad (por ejemplo, la burocracia excesiva y el acceso a terrenos con la dimensión económica; la relación y comunicación con el vecindario con la dimensión social; la contaminación o las formas de evitarla con la dimensión ambiental), aunque algunas percepciones y experiencias mostradas están relacionadas con dos o tres dimensiones a la vez.

\subsection{Dimensión económica de la sostenibilidad}

En contraste con la inmigración estrictamente de tipo laboral hacia áreas rurales (Domingo y Bernad, 2017; Hoggart y Mendoza, 1999; Julià Traveria et al., 2020), la construcción de redes empresariales y sociales de cooperación en el territorio es clave para entender la viabilidad de los negocios que llevan a cabo las personas inmigrantes entrevistadas en el Alt Empordà y que se pueden relacionar con las migraciones que conllevan un cambio de 'estilo de vida'. El papel de las redes personales para la creación y consolidación de empresas en zonas rurales se ha abordado en la literatura académica (p. ej., Esparcia et al., 2015; Stathopoulou, et al., 2004). En el caso del sur de Europa, esta literatura se ha enfocado en la pertenencia al territorio (y sus vínculos históricos y culturales) para articular estrategias económicas exitosas basadas en pequeñas empresas familiares (p. ej., Esparcia, 2017). Durante nuestro trabajo de campo, comprobamos la importancia de los vínculos basados en relaciones personales y en la confianza, tanto en actividades agrícolas y turísticas como en las sinergias creadas entre estos dos sectores económicos (Mendoza et al., 2020; Romagosa et al., 2020), como ilustra el siguiente fragmento de entrevista:

"Nuestro nicho de mercado es diferente, porque producimos vino ecológico. Guardamos el vino [en barricas] para el año siguiente, para obtener un sabor más suave (...) Hay dos circuitos económicos para el vino: el orientado al mercado y el no convencional. Este último está basado en amigos y conocidos (...) Los restaurantes locales nos conocen... Creo que tenemos una buena posición en el mercado. iVendimos casi todo lo que producimos el año pasado en sólo un mes!” (EC\&AMB-28-Países Bajos-Mujer).

En contraste con las oportunidades que ofrecen las redes presenciales de carácter personal mencionadas, las personas entrevistadas ponen de manifiesto la existencia de varios desafíos económicos y tecnológicos vinculados a las redes virtuales. Así, un reto importante para la sostenibilidad económica en los micropueblos son las 
comunicaciones telemáticas y, particularmente, obtener un acceso relativamente rápido a Internet:

"Para mí, la comunicación es muy, muy poco confiable... Internet... el teléfono también. Si yo quiero llamar... por teléfono, imposible. Yo tengo que mandar un mensaje y depende donde estoy... Si tengo cobertura, lo puedo mandar... Es un desastre" (SC-62-Nicaragua-mujer).

"Los cortes en Internet para mí son frecuentes, si lo comparo con lo que había vivido antes... Aquí se va cortando, cortando, cortando. Sí que nos llega Internet, aunque estamos una poco aislados a nivel de comunicaciones" (SC\&EC-32Canadá-mujer).

La fibra óptica (considerada como más fiable y segura que el ADSL o los enlaces por radio) se ha ido extendiendo por algunos municipios de la comarca ${ }^{16}$, aunque todavía quedan casi todos los micropueblos del Alt Empordà por conectar, puesto que, hasta finales de 2020, la prioridad para el gobierno de la Generalitat de Catalunya han sido municipios más poblados. Sin embargo, a finales de febrero de 2021, la empresa Goufone anunció que un micropueblo del Alt Empordà, Viladamat, ya disponía de fibra óptica ${ }^{17}$. Está por ver si esta incipiente tendencia se consolidará o no durante los próximos años. En cualquier caso, entretanto, como alternativa, la importancia de los grupos de WhatsApp (que sólo requieren un Smartphone) para la comunicación vecinal en pueblos pequeños se ha ido extendiendo con los años por diversas regiones de España (a veces fomentados por los ayuntamientos) ${ }^{18}$. En nuestra área de estudio, de hecho, la población inmigrante ha creado sus propios grupos internacionales que cuenta con gran arraigo en algunos micropueblos ampurdaneses:

"Tenemos un grupo de WhatsApp abierto al que cada vez llega más gente. Algunos somos de Canadá, otros ingleses y franceses, unos de Madrid, sólo hay uno autóctono del Empordà [casado con una inmigrante], casi todos son extranjeros" (SC\&EC-32-Canadá-mujer).

Además, por otro lado, varias de las personas entrevistadas tienen claro que su proyecto económico debe tener a corto o medio plazo una adaptación a la transición

\footnotetext{
${ }^{16}$ Ver: https://politiquesdigitals.gencat.cat/ca/detalls/Noticia/Nova-Noticia-00095

${ }_{17}$ Ver: https://www.emporda.info/empreses-a-emporda/2021/02/23/fibra-optica-goufone-contribueixdesenvolupar/488406.html

${ }^{18}$ Ver: https://www.cmmedia.es/noticias/castilla-la-mancha/todo-un-pueblo-conectado-por-whatsappasi-es-la-comunicacion-en-almodovar-del-pinar-cuenca/
} 
ecológica ${ }^{19}$ pero algunos retos económicos a superar pueden ser tanto conseguir terrenos con infraestructura donde realizar el proyecto de negocio como reclutar mano de obra para las épocas de mayor actividad empresarial y colocar productos en mercados internacionales. En la línea de lo que auguraba Camarero (1996, p. 125), en comarcas como el Alt Empordà, el campo no es (aún) "un residuo en la conquista de la modernidad que sería urbana e industrial”, pero la agroindustria ha crecido a veces gracias a la llegada de emprendedores inmigrantes internacionales (Mendoza et al., 2020):

\begin{abstract}
"Pasamos un año buscando un terreno que tuviese agua y gas... Desde la nada hemos construido una fábrica... Hay un pozo y hemos puesto la maquinaria moderna necesaria para sacar agua, una balsa para regar, para guardar agua, para hacer un circuito de agua renovable, placas solares. Todo va con energías renovables menos el boiler porque, claro, necesitas una presión importante y hacerlo con leña es brutal... y entonces es con gas. Pero la intención es que, en 5 o 6 años, cuando ya podamos comprar baterías Tesla, todo será renovable. Y plantamos las plantas... a mano con el calendario biodinámico, a mano. Bueno, con gente [inmigrada] de Senegal y de Marruecos, con workaways de Estados Unidos en verano... y iademás nuestros hijos!... Vendemos en Francia e Inglaterra, a compañías pequeñas y a compañías enormes" (EC\&SC-40-Reino Unido-mujer).
\end{abstract}

A pesar de tratar de retos para el desarrollo de un negocio con ánimo de lucro, el fragmento de entrevista anterior también pone de manifiesto cómo la sostenibilidad es tridimensional, confluyendo cuestiones económicas, sociales y ambientales (por ejemplo, Adams, 2006; Morén-Alegret y Wladyka, 2020), como el acceso a infraestructuras energéticas y a mano de obra, la conciliación familiar o la disponibilidad de tecnología limpia. En el siguiente apartado se pone el énfasis en cuestiones más directamente relacionadas con la dimensión ambiental.

\title{
4.2. Dimensión ambiental de la sostenibilidad
}

Una de las cuestiones ambientales destacadas durante las entrevistas es la contaminación de acuíferos que afecta algunos pueblos de la comarca y de otras partes del país a causa, entre otros factores, de ciertas prácticas de la agricultura y la ganadería intensiva. En lugares de clima mediterráneo como el Alt Empordà, esta contaminación de acuíferos combinada con efectos del cambio climático como el aumento de las sequías

\footnotetext{
19 La transición ecológica recientemente también está promovida por el gobierno español (ver: https://www.miteco.gob.es/es/) y se puede relacionar con el European Green Deal promovido por la Comisión Europea (https://ec.europa.eu/info/strategy/priorities-2019-2024/european-green-deal en).
} 
(Fatorić et al., 2017) puede convertirse en un gran reto para la sostenibilidad, particularmente difícil de superar:

"[en este pueblo] tenemos una granja que se construyó ilegalmente porque legalmente no se puede construir una granja a menos de tres kilómetros de otra. Para solucionar este problema, se hizo un pago para que una persona dijese que esa granja es suya. Entonces esta empresa, los amos de esta macro granja tienen 8000 cerdos, aquí, que es una zona muy seca. Estos cerdos engordan aquí, dejan los purines aquí, y luego se van a Holanda. Este problema es un problema para toda Cataluña y quizás para España, es un problema muy grave... si se tratase este tema y se pusiese en marcha las safecards para vigilar, no hay problema. Pero hay un abuso del sistema... los que sufrirán no somos nosotros, sino nuestros hijos y nietos porque están contaminando el agua del subsuelo. En un país donde falta agua, eso es terrible.... Ya puedes tener todas las leyes del mundo, pero si no se implementan, ¿qué se puede hacer?” (SC-71-Alemania-mujer).

En este sentido, desde una organización ecologista relevante a escala comarcal y con influencia a nivel catalán, confirmaban en otra entrevista que dichas preocupaciones son también compartidas entre parte de la población nacida en la comarca e inmigrantes internos procedentes de otras partes de Cataluña y del resto de España:

[Las granjas porcinas] es uno de los grandes temas... Sí, en Palau de Santa Eulàlia hubo un proyecto... En Cantallops tenemos tres granjas en las que estamos trabajando... Independientemente de si son micropueblos o no, tenemos 34 municipios contaminados por nitratos [en la comarca]... El 2002 teníamos 300.000 cerdos y ahora tenemos hacia 500.000 y las tramitaciones no se paran, es un drama ... Todas las granjas están dentro de las empresas integradas... El problema es que los que son payeses y hacer granjas es la manera de subsistir bien... Te sacas 2.00o euros al mes. Estos son los cálculos que siempre nos dicen ellos, es la forma de vivir del campo. Por eso, todo el mundo está haciendo granjas y por eso la Generalitat está dando permisos a prácticamente todo el mundo, de una manera muy irregular. La Generalitat está intentando frenarlo, pero es difícil...” (AMB-40-España-mujer).

Además de la vía gubernamental, la vía judicial está siendo también una opción para lidiar con algunos casos de contaminación de acuíferos por excrementos porcinos. Por 
ejemplo, en febrero de 2021 el juzgado contencioso administrativo de Girona ${ }^{20}$ condenó al Ayuntamiento de Cantallops a incoar un expediente de clausura de la granja Noguers por "falta de titulación habilitante" y a iniciar un expediente sancionador para "depurar las responsabilidades" derivadas del funcionamiento "irregular" de la explotación. La sentencia también ordenó incoar un expediente para declarar caducada la licencia ambiental por falta de control inicial favorable y diversos incumplimientos, como la falta de capacidad suficiente para almacenar excrementos porcinos. Se trata de procesos judiciales lentos y complejos, pero que a veces dan resultados bien valorados por habitantes con sensibilidad ambiental tanto nacidos en la comarca como inmigrantes llegados a micropueblos ampurdaneses por motivos de cambios de estilo de vida.

Más allá de la cuestión de los residuos de granjas porcinas intensivas, hay la cuestión más general del tratamiento de las aguas residuales en áreas rurales. Según la Agencia Catalana del Agua (ACA, 2018), cerca del 3\% de la población humana catalana y centenares de municipios (rurales) todavía no tienen acceso a plantas de tratamiento de agua residual: en junio de 2020 el Plan de Saneamiento de Cataluña incluía 526 plantas de tratamiento que saneaban el agua para el $97 \%$ de la población catalana. Más recientemente, Marta Subirana, la Secretaria de Medioambiente del gobierno catalán indicó en un periódico financiero que se necesitan aproximadamente 1000 acciones y 1000 millones de euros para finalizar el plan de saneamiento en lugares (rurales) donde alrededor del 2\% de la población catalana reside (Elcacho, 2020). En cuestiones de gestión del agua, ha habido un sesgo urbano (Saurí y Arahuetes, 2019). Así pues, si a partir de ahora realmente se quiere fomentar a nivel político y gubernamental la repoblación de los micropueblos, es importante tener en cuenta si los municipios cuentan ya con instalaciones adecuadas para el saneamiento de agua, para evitar que nuevos pobladores aumenten la contaminación.

En contraste con los empresarios agrícolas de la comarca que entran en estas dinámicas de cría porcina enmarcadas en sistemas de producción integrada y vertical, en los últimos tiempos, también han surgido en el Alt Empordà otras iniciativas agrícolas de colaboración horizontal (en las que participan algunos inmigrantes), como se exponía también en febrero de 2021 en un reportaje del relevante semanario comarcal Empordà ${ }^{21}$.

${ }^{20}$ Ver: https://www.ccma.cat/324/un-jutjat-ordena-a-lajuntament-de-cantallops-que-tanqui-una-granjaper-falta-de-titulacio/noticia/3078152/

${ }^{21}$ Ver: https://www.emporda.info/comarca/2021/o2/23/pagesia-busca-alternatives-fentxarxa/488271.html 
Por otro lado, la conciencia ecológica de algunos entrevistados también se desvela cuando destacan el reto que puede suponer para la sostenibilidad el uso de transgénicos y la agricultura intensiva en productos químicos:

"Basta con Monsanto, basta con esa porquería de fitosanitarios, basta con eso. Los propietarios de la finca tienen una finca cerca del chiringuito. Tienen olivos, ciento cincuenta, tienen viñedo y todo, y no hay ni hierba debajo de los olivos, nada. Tienen limones gigantes. Que ponen cosas que no son naturales, ¿̇sabes? (...) Ahora la generación de los jóvenes que reciben o compran a los padres una finca que sea de árboles o algo, quizás sean un poco más listos para intentar la cultura 'bio'. Pero es una cuestión de generación y de educación también (...) el producto quizás lo pagas un euro o dos euros más por el trabajo, pero, mira, la calidad está. Quizás hay que esperar un poco a que la economía del país esté mejor para que la gente tenga ganas de hacerlo porque también es un lujo. En un país no digo más desarrollado, pero sí con más dinero, como por ejemplo Suiza, claro, casi todo es 'bio' porque es posible. Y la protección de la naturaleza en Suiza es una tradición. ¿Por qué? Ni guerra, ni nada. Es algo que se puede hacer. Es como escuchar música: no es útil, pero es indispensable" (SC-62-Suiza-hombre).

Sin embargo, otro hecho también es que, a pesar de esa percepción y de problemas como la contaminación de acuíferos antes mencionados, en España la superficie de cultivos de agricultura ecológica ha crecido de forma destacada en los últimos años ${ }^{22}$, pasando a convertirse en el tercer país del mundo con mayor superficie agroecológica (por detrás de Australia y Argentina) ${ }^{23}$.

En este contexto, además de la protesta por contaminación uniéndose a diversas plataformas o entidades ambientales junto con habitantes de la comarca que llevan décadas de activismo, algunos inmigrantes se implican proponiendo mejoras concretas a nivel personal en las prácticas agrarias de habitantes nacidos en el pueblo, para que sean más ecológicas:

"Pocos tienen placas solares. Nuestro vecino trabaja en las viñas, hace viticultura con muchos pesticidas. Yo quiero ser amiga de él y le he explicado lo que necesita. No quiero decirle que lo que hace está mal, pero quiero explicárselo" (EC\&AMB28-Países Bajos-mujer).

\footnotetext{
${ }^{22}$ Ver: https://www.mapa.gob.es/es/prensa/ultimas-noticias/la-superficie-ecológica-crece-el-48--en-2019y-se-sitúa-en-235-millones-de-hectáreas/tcm:30-541106

${ }^{23}$ Ver: https://www.agroecologia.net/estadisticas-agricultura-ecologica-mundial-fibl-ifoam-biofach/
} 
Morén-Alegret, R. y Mendoza, C.

Aunque se puede seguir estando de acuerdo en que "en general, se parte del ámbito local para definir una buena práctica agraria” (Gómez Mendoza, 2001, p. 143), las

relaciones detectadas entre agricultores nacidos en tierras ampurdanesas y agroemprendedores inmigrantes, invitan a resaltar que lo que hoy se considera como 'local' puede incluir tanto a nacidos en el lugar como a inmigrantes de diversos orígenes y edades.

\subsection{Dimensión social de la sostenibilidad}

De forma parecida a otras áreas rurales (Blay, 2020), el impactante envejecimiento poblacional y el relativo aislamiento son algunos de los retos actuales en micropueblos del Alt Empordà, como explicó un profesional sanitario con experiencia internacional:

"La gente mayor tiene dificultades para trasladarse y no tiene una tienda que dé servicio. A lo mejor desde el punto de vista económico, no interesa, pero sí socialmente, y eso lo veo en varios pueblos de la comarca. Se debería tener una visión no sólo económica, sino también social. Además, generaría trabajo para la gente... Un problema es la soledad. Me vienen a ver aquí, porque están solos. Tienen hijos, pero no los visitan. Están solos” (SC-44-Argentina-hombre).

La sensación de aislamiento se acrecienta con la dificultad de las comunicaciones. En contraste con la inmigración 'por estilo de vida', esa soledad relacionada con la despoblación y el relativo aislamiento geográfico puede llevar al miedo o la rural-fobia (Morén-Alegret, 2008) entre algunos inmigrantes laborales que residen o trabajan en micropueblos y que han vivido anteriormente en lugares más poblados (adonde algunos preferirían volver si pudiesen):

"No hay gente. Tengo miedo de que me pase algo, que me pase algo y me quede aquí tirado. El ayuntamiento tampoco está abierto. Vienen cuatro o cinco horas, y se van. No hay ni un bar, ni tienda. El local no está abierto. No hay gente... Aquí hay cuatro viejos y se meten en su casa" (EC-54-Marruecos-hombre).

Diseñar programas sociales a nivel comarcal o municipal para detectar esos casos de miedo o rural-fobia entre inmigrantes y acompañar a las personas que necesiten apoyo emocional podría ayudar a conseguir una mayor ratio de retención de población inmigrante en áreas rurales.

A otro nivel comunicacional, a pesar de que la comarca cuenta con una nutrida red de carreteras, los habitantes de los micropueblos necesitan, en muchos casos, de un vehículo privado para desplazarse, lo cual puede ser de especial importancia para 
personas de edad avanzada. En particular, los servicios básicos de salud están cubiertos en los micropueblos, pero los más especializados, como hospitales, se concentran en ciudades medias o grandes. De hecho, se puso de manifiesto que algunas personas de edad avanzada optaban por vender sus casas en los pequeños pueblos para comprar apartamentos en las ciudades y así estar más cerca de los servicios de salud (Mendoza et al., 2020). El siguiente fragmento de entrevista a una mujer belga que compara los servicios asistenciales de la comarca con los de su país de origen ilustra esta problemática:

"En Bélgica, existe un autobús que lo llamas cuando lo necesitas. Es mucho mejor que una línea normal. Así es incluso más barato. Mi padre necesitaba ir al médico todos los días, y tenía ese servicio. También se necesita una enfermera en nuestros pueblos, alguien que pueda ir a casa. Aquí prácticamente todas las personas pagan una enfermera. Una enfermera gratuita pagada con dinero público no es un servicio para todos; es sólo para los pobres. Tuve un accidente y no pude salir de casa por un tiempo. Pedí una enfermera al Ayuntamiento y me pidieron el salario. Su respuesta fue que el servicio está restringido a las personas de escasos recursos. Pero, iuna enfermera no es un lujo!” (SC-58-Bélgica-mujer).

Sin embargo, con referencia a las oportunidades que ofrecen algunos micropueblos, también existe población (tanto nativa como inmigrante) que se adapta a la vida rural relativamente tradicional que conlleva una menor cultura de visitas médicas periódicas, especialmente cuando se aprecian las ventajas para la salud humana de contar con un entorno natural protegido:

“[En los pueblos] creo que el servicio médico es bueno. En la zona más rural a las personas no les gusta ir tanto al médico, no es como en las ciudades, que parece que haya que ir al médico por cualquier cosa. Van al médico de manera correcta. Tienen consciencia de salud, están en contacto con la naturaleza y saben cuidarse. Conocen algunas plantas medicinales. Aquí, al lado, está el parque natural, con su jardín de plantas medicinales" (SC-44-Argentina-hombre).

La tranquilidad y la seguridad son también un atractivo de los micropueblos para algunas familias inmigrantes con niños, como ilustra el siguiente fragmento de entrevista:

"Vivimos en el núcleo del pueblo. Es importante para nosotros vivir en el pueblo. Para los niños es fantástico, tienen un montón de independencia, pueden 
moverse libremente alrededor del pueblo, van con sus amigos por ahí” (EC-41Reino Unido-mujer).

Sin embargo, las dificultades de la juventud nativa para quedarse a vivir en el pueblo y la dificultad para atraer (y retener) más inmigración de familias con niños o jóvenes emprendedores (Vitores et al., 2020) son algunos de los otros retos sociales actuales planteados por algunas personas entrevistadas, pero son retos que, con mejoras en las políticas locales y comarcales, se considera que pueden devenir en oportunidades para una mayor repoblación rural:

"Podría haber más negocios locales, como panaderos o mecánicos. Debería haber más apoyo para que la gente joven se dedicara a ello aquí porque supongo que los jóvenes necesitarían (bastante) dinero para empezar esos negocios... Sólo hay una tienda, una carnicería... es más cara [que el supermercado de la ciudad]. Me pregunto si la tienda continuará, no sé si los hijos de quienes la regentan continuarán con ella. Me gustaría” (EC-41-Reino Unido-mujer).

En este contexto, el difícil acceso a la vivienda en general y, en particular, para la gente joven es algo muy destacado por entrevistados de diversos orígenes ubicados en distintos micropueblos:

"Las casas son muy caras y... entonces la gente joven no puede pagarse las casas. Es este el problema que veo. Tenemos casas que se están cayendo y no las podemos comprar porque son demasiado caras. Nos da la sensación que no hay suficientes recursos legales [en el ayuntamiento] como para gestionar un poco los alquileres, hacer que sean más accesibles... Hemos estado buscando para unas amigas nuestras una casa de alquiler y hay muchas casas vacías que son heredadas y los hijos no se ponen de acuerdo. Por tanto, se quedan ahí, vacías... Ponen un precio súper alto y esperan que venga algún alemán o algún inglés que tenga el dinero" (SC\&EC-32-Canadá-mujer).

"Hay problemas de [disponibilidad de] vivienda y las que hay son bastantes caras para comprarlas y también los alquileres. [Sería positivo] si se les da posibilidad a la gente para que pueda construir su vivienda, de una forma organizada. Pero tampoco estaría bien crecer de una forma desorganizada, porque [el pueblo] perdería identidad y esencia" (SC-44-Argentina-hombre).

En octubre de 2020, estas cuestiones fueron discutidas en una jornada sobre políticas de vivienda en municipios poco poblados, organizada por el Consorcio de la Universidad 
Internacional Menéndez Pelayo y la Diputación de Barcelona ${ }^{24}$. La mayoría de estos municipios se enfrentan a retos comunes y dificultades en la gestión de los servicios y de las políticas debido a la falta de recursos técnicos y económicos. En este sentido, los ayuntamientos de municipios con poca población manifestaron en dicho foro necesidades y retos comunes como: a) la falta de vivienda asequible que dificulta la fijación y atracción de población; b) la existencia de un tejido residencial con una proporción significativa de viviendas vacías y en mal estado; c) la falta de adecuación de las viviendas a las necesidades de una parte de la población debido al envejecimiento, a la mayor longevidad vital y a la dependencia de muchos habitantes; d) la inadecuación tipológica de una parte significativa del parque residencial (por ejemplo, viviendas demasiado grandes para el tamaño reducido de muchas unidades familiares actuales); e) la necesidad de vincular el modelo residencial al modelo socioeconómico o territorial de cada lugar; f) la falta de líneas de apoyo específicamente diseñadas a las necesidades de vivienda de los pequeños municipios, poniendo atención en las diferentes situaciones de los micropueblos de montaña y los de las llanuras interiores o el prelitoral (o entre los micropueblos cercanos a las capitales de comarca y los más remotos).

Por otro lado, a nivel de oportunidades sociales, la celebración de algunas fiestas locales y ferias ofrece ocasiones para la socialización en micropueblos del Alt Empordà entre personas originarias de varios lugares:

"[un] chico catalán organizó una feria... Había mucha gente del pueblo y yo empiezo a hablar catalán, y a ellos les gusta, porque algunos tienen problemas para hablar castellano. Durante esa feria, me sentía "fixada" [arraigada], como si estuviera en casa. Mi novio no es muy bueno con las lenguas... A veces siento que él no se siente integrado, porque le cuesta hablar castellano y la gente quiere hablar catalán, y para él es muy difícil. Y a mí, me gusta hablar catalán, me siento integrada" (EC\&AMB-28-Países Bajos-mujer).

La cancelación o traspaso a la modalidad "on-line" de algunos de estos eventos debido a la pandemia de la Covid-19 está suponiendo un reto para la dimensión social de la sostenibilidad local y comarcal, aunque durante el verano de 2020 algunos festivales se pudieron celebrar al aire libre con medidas de seguridad y adaptaciones a la nueva realidad, así que todavía es pronto para conocer el impacto de la pandemia a nivel social en los micropueblos. Por ejemplo, el Festival de Artes, Sinergias, Teatro y Territorio (FASTT) apostó por la reducción de actividades, la descentralización espacial y la

\footnotetext{
${ }^{24}$ Ver: https://www.diba.cat/es/web/hua/-/jornada-sobre-pol\%C3\%ADtiques-d-habitatge-en-petitsmunicipis
} 
concentración temporal de su programación ${ }^{25}$, de manera que se celebró en tres micropueblos del Alt Empordà (Palau de Santa Eulàlia, Garrigàs y Siurana) durante una sola jornada, el 22 de agosto de $2020^{26}$ (para evitar pernoctaciones de artistas, técnicos o visitantes).

Además, como la entrevistada anterior sugería en otra parte de la conversación, el aprendizaje de lenguas tiene una relación tanto con la dimensión social como con la dimensión económica de la sostenibilidad, especialmente en contextos multilingües:

"Tengo una subvención de Agricultura y, para ello, debo hacer muchos cursos, de tractor, etcétera. Y todos esos cursos son en catalán. Por eso, estoy aprendiendo catalán” (EC\&AMB-28-Países Bajos-mujer).

La importancia del multilingüismo en las empresas catalanas como herramienta de internacionalización económica se ha puesto en valor desde hace años, como en el estudio ELAN de $\mathbf{2 0 1 0}^{27}$. Un reto es conseguir que en el ámbito rural esa puesta en valor del multilingüismo empresarial y social sea parecida a la de las áreas urbanas o metropolitanas. Algunos ejemplos de emprendedores inmigrantes sugieren que en los últimos años se ha avanzado en ese camino, al menos en el Alt Empordà.

\section{Conclusiones}

En este estudio se destaca que, entre la inmigración internacional que reside en los micropueblos del Alt Empordà y que procede mayoritariamente de otros países de Europa o de las Américas (incluyendo emprendedores y empresarios, así como trabajadores experimentados), se pueden escuchar voces cualificadas que plantean diversos retos para la sostenibilidad local, así como oportunidades para el presente y el futuro. Si realmente se quieren diseñar políticas efectivas de repoblación rural, sería interesante tenerlas en cuenta.

En este sentido, algunos de los retos (y dificultades) para la sostenibilidad de los micropueblos que hay en el Alt Empordà según la percepción de diversos inmigrantes internacionales son:

\footnotetext{
25 Ver: https://www.emporda.info/cultura/2020/o7/29/garrigas-siurana-palau-santaeulalia/471453.html

${ }^{26}$ Ver: http://www.horanova.cat/el-fastt-fa-gran-el-teatre-de-micropobles/

27 Ver:

https://llengua.gencat.cat/ca/serveis/informacio i difusio/publicacions en linia/classific temes/temes opuscles divulgatius/multilinguisme empreses elan opuscle/
} 
R1) Acceder a mejores comunicaciones virtuales y particularmente un acceso rápido a Internet.

R2) Conseguir más terrenos con infraestructura adecuada (como conexión a canalizaciones de gas o tecnología ecológica) donde realizar proyectos de negocios multidimensionales y que se puedan enmarcar en el 'green deal' de la Unión Europea.

R3) Mejorar la información y los canales disponibles para reclutar mano de obra en las épocas de mayor actividad empresarial y para colocar productos en mercados internacionales.

R4) Acabar con la contaminación de acuíferos que afecta algunos pueblos de la comarca y de otras partes del país, causada entre otros factores por ciertas prácticas de la agricultura y la ganadería intensiva (como algunas granjas porcinas), así como por la falta de suficientes plantas de tratamiento de aguas residuales.

R5) Superar la falta o escasez de algunos servicios y de viviendas en los micropueblos, pues a veces requiere de un esfuerzo extraordinario de adaptación y resistencia por parte de los nuevos pobladores, algunos de los cuales desisten de continuar con el empeño.

Por otro lado, algunas oportunidades planteadas durante las entrevistas para fomentar la sostenibilidad de los micropueblos en relación con la llegada de inmigración internacional son:

O1) A nivel económico y social, el poder establecer mejores vínculos humanos basados en relaciones personales y en la confianza cercana entre personas de diversos orígenes geográficos. Estas relaciones pueden contribuir a desarrollar actividades agrícolas y turísticas sostenibles e innovadoras, así como sinergias estos dos sectores económicos u otros como el educativo.

O2) Para la implementación de la transición ecológica promovida por la Comisión Europea, contar en municipios con baja densidad de población con vecinos de varios países de la UE formados en agricultura ecológica o en ingeniería ambiental y que hablan varias lenguas internacionales puede ser una ventaja competitiva para redactar proyectos sostenibles que atraigan fondos.

O3) La tranquilidad y la seguridad son un atractivo potencial de los micropueblos para algunas familias inmigrantes con niños, por lo que si se consigue pasar más de la 
potencia al acto migratorio ( $\mathrm{y}$ al asentamiento) de forma sostenible pueden generarse oportunidades para crear nuevos negocios y servicios rurales.

O4) Los entornos naturales con alto valor ecológico de algunos micropueblos generan oportunidades para desarrollar más actividades económicas y sociales vinculadas a un estilo de vida más respetuoso con la naturaleza.

O5) La escasez o ausencia de viviendas habitables ofrece oportunidades de negocio para la rehabilitación ecológica y actualizada de casas antiguas (o de ruinas), así como para la construcción de nuevas viviendas más sostenibles.

Esta variedad de retos y oportunidades apuntadas en entrevista muestran el interés por parte de algunos inmigrantes internacionales residentes en el desarrollo sostenible de los micropueblos ampurdaneses. En general, por tanto, no son un colectivo pasivo, sin interés en las actividades económicas, el bienestar social o el entorno ambiental de estos municipios, sino que son personas que cuentan con una opinión argumentada sobre el lugar en el que viven. Sugieren, sin duda, ideas de cambio (y de mejora), sobre el medio local rural. Mientras que estas personas inmigrantes se pueden encarrilar hacia proyectos económicos creativos que permiten interrelación de diferente orden con los agentes locales nativos, las dimensiones sociales y especialmente ambientales son de más difícil trato, dado que la población inmigrante, en general, cuenta con menos mecanismos formales e informales de participación política. Un reto para la gobernanza municipal en los micropueblos se ubicaría, pues, en poder articular formas de participación de las personas no nacidas en estos territorios y, cuando sea necesario, superar desconfianzas de una parte de la población nativa con respecto a las personas inmigrantes: que éstas sean vistas como lo que son en un buen número de ocasiones, agentes de transformación e incluso de garantía de supervivencia de sus propios municipios. 


\section{Referencias}

ACA (2018). El sanejament a Catalunya. Un model pioner, Barcelona: Agència Catalana de l'Aigua, Generalitat de Catalunya.

Adams, W. M. (2006). The Future of Sustainability. En VVAA Report of the International Union for the Conservation of Nature Renowned Thinkers Meeting (pp. 1-18). Gland: IUCN.

Badia, A., Pèlachs, A., Vera, A., Tulla A.F., \& Soriano J.M. (2014). Cambios en los usos y cubiertas del suelo y los efectos en la vulnerabilidad de las comarcas de montaña de Cataluña. Pirineos, $169, \quad$ DOI: http://dx.doi.org/10.3989/Pirineos.2014.169001

Bartoš, M., Kušová, D. y Těšitel, J. (2009). Motivation and lifestyle of the Czech amenity migrants. European Countryside, 1(3), 164-179.

Bayona-i-Carrasco, J. y Gil-Alonso, F. (2013). Is foreign immigration the solution to rural depopulation?. Sociologia Ruralis, 53(1), 26-51.

Blay, J. (2020). Noves ruralitats: una aproximació als canvis en les activitats econòmiques de les zones rurals catalanes en els darrers 50 anys. Treballs de la Societat Catalana de Geografia, 9o, 115-128.

Bosworth, G. y Farrell, H. (2011). Tourism entrepreneurs in Northumberland. Annals of Tourism Research, 38(4), 1474-1494.

Bruckmeier, K. y Tovey, H. (2009) Introduction. Natural Resource Management for Rural Sustainable Development. En K. Bruckmeier y H. Tovey (eds.) Rural Sustainable Development in the Knowledge Society (pp. 1-19). Farnham/Burlington: Ashgate.

Camarero, L. (1996). El mundo rural en la era del ciberespacio. En M.A. García de León (ed.) El campo y la ciudad (pp. 123-151). Madrid: Ministerio de Agricultura Pesca y Alimentación.

Camarero, L. (2020). Despoblamiento, baja densidad y brecha rural: un recorrido por una España desigual, Panorama Social, 31, 47-73.

Carson, D. A., Carson, D.B. y Eimermann, M. (2018). International winter tourism entrepreneurs in northern Sweden. Scandinavian Journal of Hospitality and Tourism, 18(2), 183-198.

Cloke, P. (1983) An Introduction to rural settlement planning, Nueva York: Routledge Revivals ( $2^{\text {a }}$ edición, 2013).

Cloke, P. (1979). Key settlements in rural areas, Londres: Routledge ( $2^{\mathrm{a}}$ edición, 2013).

Cloke, P. y Milbourne, P. (1992). Deprivation and lifestyles in rural Wales. Journal of Rural Studies, 8(4), 359-371.

Colegio de Geógrafos de Cataluña (2013). Micropobles. Elements per a un debat, Barcelona: Col-legi de Geògrafs de Catalunya. 
Collantes, F., Pinilla, V., Sáez, L. A. y Silvestre, J. (2010). El impacto demográfico de la inmigración en la España rural despoblada. Boletín Elcano (128). http://biblioteca.ribei.org/id/eprint/200o/1/DT-30-2010.pdf

Collantes, F., Pinilla, V., Sáez, L. A. y Silvestre, J. (2014). Reducing depopulation in rural Spain: The impact of immigration. Population, Space and Place, 2O(7), 606-621.

DARPA (2020). Observatori del Món Rural 202O, Barcelona: Departament d'Agricultura, Pesca i Alimentació, Generalitat de Catalunya.

Delgado Serrano, M. M. (2004). La política rural europea en la encrucijada. Madrid: Ministerio de Agricultura Pesca y Alimentación.

Domingo, J. y Bernad, O. (2017). Inmigración africana en el contexto rural de Cataluña, Revista Internacional de Estudios Migratorios, 7(1), 9-45.

Elcacho, J. (2020). Invertir en saneamiento y gestión del agua, un reto global y local, La Vanguardia. Dinero, 22, 17-18.

Ely, M., Vinz, R., Downing, M. y Anzul, M. (1997). On Writing Qualitative Research. Living by Words, Londres / Washington D.C.: Falmer Press.

Esparcia, J., Escribano, J. y Serrano, J. J. (2015). From development to power relations and territorial governance. Journal of Rural Studies, 42, 29-42.

Esparcia, J. (2017). Capital social y desarrollo territorial: Redes sociales y liderazgo en las nuevas dinámicas rurales de España. Bellaterra: Universitat Autònoma de Barcelona. Tesis de doctorado.

Espiña, Y. (2011). 'Sustentabilidade e Progresso'. En C. Soares et al. (eds.) A Sustentabilidade do Planeta (pp. 11-22), Leça de Palmeira, Portugal: Letras e coisas.

EUROSTAT. (2016). Sustainable development in the European Union. Luxembourg: Publications Office of the European Union.

EUROSTAT. (2017). Sustainable development in the European Union. Luxembourg: Publications Office of the European Union.

Fatorić, S., Morén-Alegret, R., Niven, R. J. y Tan, G. (2017). Living with climate change risks, Environment Systems and Decisions, 37(3), 276-288.

FAO. (2018). Family faming knowledge platform. Roma: Food and Agriculture Organization, Naciones Unidas. Garriga, A. (2020). Evolució de l'economia gironina. Període 2008-2018, Girona: Universitat de Girona / Fundació 'la Caixa' / Diputació de Girona (https://www.ddgi.cat/web/recursos/document/8718/8985/Informe Final Evolucio de 1 economia Gironina 2008-2018.pdf)

Glaeser, E. (2012). Triumph of the City. Londres: Penguin Books.

Gómez Mendoza, J. (2001) Las ‘nuevas' funciones socioeconómicas y medioambientales de los espacios rurales. En F. García Pascual (coord.). El mundo rural en la era 
de la globalización: Incertidumbres y potencialidades (pp. 111-148), Madrid: Ministerio de Agricultura Pesca y Alimentación / Universitat de Lleida.

González-Hidalgo, M., Otero, I. y Kallis, G. (2014) Seeing beyond the smoke: The political ecology of fire in Horta de Sant Joan (Catalonia). Environment and Planning A, 46(5), 1014-1031.

Halfacree, K. (2008). To Revitalise Counterurbanisation Research? Recognising an International and Fuller Picture. Population, Space and Place, 14(6), 479-496.

HAMLETS (2019) Hamlets. Inmigración y desarrollo sostenible en los micropueblos: Bellaterra (Barcelona): Universidad Autónoma de Barcelona, UAB: https://ods.cat/es/hamlets-inmigracion-y-desarrollo-sostenible-en-losmicropueblos/

Hedlund, M., Carson, D.A., Eimermann, M. y Lundmark, L. (2017). Repopulating and revitalising rural Sweden?. Geographical Journal, 183(4), 400-413.

Hoggart, K. y Mendoza, C. (1999). African immigrant workers in Spanish agriculture. Sociologia Ruralis, 39(4), 538-562.

Institut d'Estadística de Cataluna (2021). Padrón Municipal de Habitantes. Barcelona: IDESCAT. http://www.idescat.cat/pub/?id=pmh\&geo=com\&lang=es

Institut d'Estadística de Catalunya (2020a). Censos de Población y Vivienda. IDESCAT. https: / www.idescat.cat/pub/?id=aec\&n=312\&lang=es\&t=2011

Institut d'Estadística de Catalunya (2020b). Censos Agrícolas. IDESCAT. https://www.idescat.cat/pub/?id=aec\&n=424\&lang=es

Instituto Nacional de Estadística (2019) Padrón. Población por municipios, Madrid: INE. https://www.ine.es/dyngs/INEbase/listaoperaciones.htm

Iversen, I. y Jacobsen, J. K. S. (2017). Migrant tourism entrepreneurship in rural Norway. Scandinavian Journal of Hospitality and Tourism, 16(4), 484-499.

Julià Traveria, R., Gónzález Rodríguez, A. y Miranda Ruche, X. (2020). El empresariado agrícola ante la inmigración: una mirada retrospectiva en el territorio de Lleida para el periodo 2005-2015. Revista Internacional de Estudios Migratorios, $10(1), 96-127$.

Juniper, T. (2015). What nature does for Britain. Londres: Profile Books.

Kasimis, C. (2010). Demographic trends in rural Europe and international migration to rural areas. Agriregionieuropa, 6(21), 1-4.

Kordel, S., Weidinger, T. y Jelen, I. (2018). Processes of Immigration in Rural Europe, Newcastle-upon-Tyne: Cambridge Scholars Publishing.

Mattsson, K. T. y Cassel, S. H. (2019). Immigrant entrepreneurs and potentials for path creating tourism development in rural Sweden. Tourism Planning \& Development. doi: 10.1080/21568316.2019.1607543

McAreavey, R. y Argent, N. (2018). Editorial. New Immigration Destinations (NID). 
Journal of Rural Studies, 64, 148-152.

Mendoza, C., Morén-Alegret, R. y McAreavey, R. (2020). Emprendimiento e inmigración internacional en áreas rurales de España, Investigaciones Geográficas, doi:10.14350/rig.60172

Morén-Alegret, R. (2008). Ruralphilia and urbophobia versus urbophilia and ruralphobia? Lessons from immigrant integration processes in small towns and rural areas in Spain. Population, Space and Place, 14(6), 537-552.

Morén-Alegret, R. y Wladyka, D. (2020). International Immigration, Integration and Sustainability in Small Towns and Villages. Londres: Palgrave Macmillan / Springer.

Morén-Alegret, R., Fatorić, S., Wladyka, D., Mas, A. y Fonseca, M. L. (2018). Challenges in achieving sustainability in Iberian rural areas and small towns, Journal of Rural Studies, 64, 253-266.

Mosler Vidal, E. (2018). Migration and the 2030 Agenda, Ginebra: IOM.

Munkejord, M. C. (2017). Becoming spatially embedded. Entrepreneurial Business and Economics Review, 5(1), 111-130.

Playà Maset, J. (2015). La població empordanesa i la immigració (1960-2014), Annals de l'Institut d'Estudis Empordanesos, 46, 237-251.

Portney, K. E. (2015). Sustainability. Cambridge/Londres: The MIT Press.

Ragin, C. C. (1994). Constructing Social Research, Thousand Oaks: Pine Forge Press.

Reher, D. S. y Requena, M. (2009). Las múltiples caras de la inmigración en España, Madrid: Alianza editorial.

Romagosa, F., Mendoza, C., Mojica, L. y Morén-Alegret, R. (2020). Inmigración internacional y turismo en espacios rurales. Cuadernos de Turismo, 46(2), 319347.

Rosenzweig, C., Solecki, W. D., Romero-Lankao, P., Mehrotra, S., Dhakal, S., \& Ibrahim, S. A (2016). Climate Change and Cities. Cambridge: Cambridge University Press.

Rye, J. F. y Scott, S. (2018). International labour migration and food production in rural Europe. Sociologia Ruralis, 58(4), 928-952. Saurí, D. y Arahuetes, A. (2019). Water reuse: A review of recent international contributions and an agenda for future research. Documents d'Anàlisi Geogràfica, 65(2), 399-417.

Scott, K., Park, J. y Cocklin, C. (2000). 'From 'sustainable rural communities' to 'social sustainability': giving voice to diversity in Mangakahia Valley, New Zealand. Journal of Rural Studies, 16(4), 433-446.

Stathopoulou S., Psaltopoulos D. \& Skuras D. (2004), Rural entrepreneurship in Europe:A research framework and agenda, International Journal of Entrepreneurial Behavior \& Research, 10, pp. 404-425. 
Tulla, A. F. (2019). Sustainable rural development requires value-added activities linked with comparative advantage: the case of the Catalan Pyrenees. European Countryside, 11(2), 229-256.

Vitores, M., Fernández, M. y Caro, R. (2020). Migrant entrepreneurship in Spain. Revista Internacional de Estudios Migratorios, 10(1), 1-39.

UN. (2014). World urbanization prospects: The 2014 revision-Highlights (ST/ ESA/SER.A/352). Nueva York: United Nations, Department of Economic and Social Affairs, Population Division.

Wall, D. (1999). Earth First! and the Anti-Road Movement, Londres/Nueva York: Routledge.

Woods, M. (2016). International Migration, Agency and Regional Development in Rural Europe. Documents d'Anàlisi Geogràfica, 62(3), 569-593.

Yeasmin, N. (2016). The determinants of sustainable entrepreneurship of immigrants in Lapland. Entrepreneurial Business and Economics Review, 4(1), 129-159.

Zovko, M. (2019). Itinerarios narrativos de la inmigración actual en España. Bellaterra: Universitat Autònoma de Barcelona. 